\title{
Analisis Perbedaan Kemampuan Bank Shoot Dari Sisi Kanan Dan Sisi Kiri Pada Anggota Ekstrakurikuler Bolabasket Putra Usia 11- 14 Tahun Di Yogyakarta
}

\author{
Kukuh Hardopo Putro \\ Program Studi Ilmu Keolahragaan, Program Pascasarjana, Universitas Negeri Yogyakarta \\ Jl. Colombo No. 1, Karangmalang Depok, Sleman, Yogyakarta, Indonesia \\ kuhapsport@gmail.com
}

\begin{abstract}
Abstrak
Permasalahan yang terjadi dalam penelitian ini adalah anggota ekstrakurikuler bolabasket putra usia 11-14 tahun di yogyakarta belum sempurna dalam melakukan bank shoot baik dalam posisi maupun gerakan. Penelitian ini bertujuan untuk mengetahui perbedaan kemampuan bank shoot dari sisi kanan dan dari sisi kiri pada anggota ekstrakurikuler bolabasket putra usia 11-14 tahun di Yogyakarta. Penelitian ini merupakan penelitian deskriptif dengan metode survei. Sampel dalam penelitian ini diambil secara random sampling, yang berjumlah 30 siswa. Instrumen penelitian menggunakan tes bank shoot dari AAHPER dengan validitas 0,609 dan reliabilitas 0.757. Teknik pengumpulan data dengan metode tes dan pengukuran. Analisis data dengan ujji prasyarat dan uji t. Hasil uji statistik diperoleh nilai uji-t bank shoot sisi kanan dan kiri memiliki nilai $t$ hitung -1,417 dan nilai $\mathrm{t}$ tabel dengan df 14 pada taraf signifikansi $5 \%$ sebesar 2,14. $\mathrm{p}=0,178$, karena $\mathrm{p}>0,05$ maka tidak terdapat perbedaan yang signifikan. Sehingga dapat disimpulkan bahwa tidak terdapat perbedaan yang signifikan antara kemampuan bank shoot dari sisi kanan dan kiri pada anggota ekstrakurikuler bolabasket putra usia 11-14 tahun di Yogyakarta.
\end{abstract}

Kata kunci : Perbedaan, Bank Shoot, Sisi Kiri, Sisi Kanan, Bolabasket

\section{Analysis of the Difference in the Capability of Bank Shoot From the Right and Left Side of Male Bolabasket Extracurricular Members Aged 11-14 Years Old in Yogyakarta}

\begin{abstract}
Problems that occur in this study are members of male basketball basketball extracurricular members aged 11-14 years in Yogyakarta not yet perfect in doing bank shoots both in position and movement. This study aims to determine the differences in the ability to shoot banks from the right side and from the left side on the extracurricular members of the basketball boy age 11-14 years in Yogyakarta. This research is a descriptive study with a survey method. The sample in this study was taken by random sampling, which amounted to 30 students. The research instrument used a bank shoot test from AAHPER with a validity of 0.609 and reliability of 0.757. Data collection techniques with test and measurement methods. Data analysis with prerequisite tests and t tests. Statistical test results obtained t-test value shoot banks right and left side has a $t$ value of -1.417 and $t$ table value with $d f 14$ at a significance level of 5\% of 2.14. $p=0.178$, because $p>0.05$ there is no significant difference. So it can be concluded that there is no significant difference between the ability to shoot banks from the right and left sides of male basketball extracurricular members aged 11-14 years in Yogyakarta.
\end{abstract}

Keywords: Difference, Bank Shoot, Left Side, Right Side, Basketball 


\section{PENDAHULUAN}

Permainan bolabasket merupakan permainan yang sangat menarik dan sangat ketat. Telah mengidentifikasi bagaimana membedakan tim yang menang dan kalah biasanya berdasarkan pada hasil yang diperoleh sebuah tim, (Choi et al., 2006; Ibanez et al., 2008; Ibanez et al., 2009; Lorenzo et al., 2010; Sampaio dan Janeira, 2003). Adapun banyak penulis menekankan pentingnya tembakan tembakan 2 point (Choi et al., 2006; Gomez et al., 2006a, b; Ibanez et al., 2009; Lorenzo et al., 2010; Sampaio dan Janeira, 2003) dan Hasil dari tembakan 3 point (Choi et al., 2006; Csataljay et al.,2012 dan 2009 ; Gomez et al., 2006a, b; Ibanez et al., 2009) sebagai faktor dalam berkontribusi kinerja tim yang dapat memenangkan pertandingan. Identifikasi dari aspek yang unik yaitu dari fisik dapat berkontribusi siknifikan untuk sukses dalam olahraga yang sudah lama diminati ilmuwan dan pelatih olahraga ini. Dalam olahraga seperti bolabasket, tinggi badan adalah keunggulan kompetitif yang jelas dan pasti.

Keistimewaan ini adalah permainan bolabasket merupakan suatu cabang olahraga yang semakin digemari oleh pelajar dan mahasiswa. Bola basket adalah olahraga intensitas tinggi yang ditandai dengan seringnya melakukan keterampilan teknis dan taktis (Conte et al.,2015;Scanlan ,Dascombe, Reaburn, \& Dalbo, 2012). Fenomena basket sudah sangat beda dari tahun ke tahun, penggemar bolabasket mulai banyak basket sampai ke kalangan anakanak dan remaja. Melalui kegiatan olahraga bolabasket ini para remaja memperoleh banyak manfaat khususnya dalam pertumbuhan fisik, mental, dan sosial. Permainan bolabasket mengalami perkembangan pesat terbukti dengan munculnya klub-klub tangguh di tanah air dan atlet-atlet bolabasket pelajar baik di tingkat sekolah maupun di perguruan tinggi dan kompetisi yang ditangani secara profesional. Berbagai kompetisi tersebut dengan sendirinya akan memunculkan bakat potensial di bidang bolabasket.

Olahraga ini merupakan olahraga yang dapat mengembangkan dimensi yang berbeda seperti karakteritik pemain dan bolabasket adalah disiplin teknis dan taktik yang kompleks, dimana efektivitas pemain dalam sebuah permainan bergantung pada penguasaan eksekusi atau perlakuan dari banyak elemen yaitu sebuah serangan dan bagaimana tim itu bertahan. Untuk alasan ini, kita memerlukan waktu yang tidak sedikit dan dapat dihabiskan untuk mempelajari berbagai teknik bolabasket adalah terbatas. Perubahan strategi membuat pemain bolabasket harus bekerja disaat yang pada paling sering digunakan dan yang paling efektif dalam melakukan sebuah tembakan. Oleh karena itu, sebuah keputusan pelatih tentang jenis tembakan atau shooting yang seharusnya dikembangkan dan dilatih dalam proses program pelatihan jangka panjang untuk menciptakan potensi ofensif pemain yang bagus (Ibáñez et al., 2008; Marmarinos et al., 2016; Okazaki et al., 2015; Raiola et al., 2016).

Olahraga bolabasket merupakan salah satu olahraga yang populer dan dipilih untuk kegiatan ekstrakurikuler di sekolah. Peminat olahraga di kalangan siswa di sekolah-sekolah juga sangat banyak bahkan termasuk ekstrakurikuler yang sangat favorit di mayoritas sekolah. Dengan adanya ekstrakurikuler bolabasket ini kegiatan ekstrakurikuler olahraga yang bersifat kegiatan fisik dapat memperdalam dan memperluas pengetahuan yang berkaitan dengan mata pelajaran pendidikan jasmani. Selain itu, kegiatan ekstrakurikuler olahraga merupakan salah satu wahana atau wadah untuk menampung, menyalurkan, dan pembinaan minat, bakat, dan kegemaran siswa dalam cabang olahraga tertentu. Disamping itu pemain bola basket remaja bertujuan untuk mencapai level elit dan profesional sangat perlu mengembangkan kinerja seperti tingkat aspek fisiologis yang tinggi (Torres-Unda et al.,2013). Melalui kegiatan ekstrakurikuler tersebut diharapkan dapat terbentuk tim yang dapat mewakili sekolah dalam kompetisi-kompetisi bolabasket.

Hasil studi pendahuluan yang telah dilakukan bulan Oktober hingga Desember 2018, setiap hari Kamis dan Sabtu di lapangan bolabasket SMK Negeri 3 Yogyakarta pada saat kegiatan ekstrakurikuler bolabasket berlangsung. Peneliti mendapati bahwa kondisi pemain 
kurang menguasai teknik shooting terutama untuk bank shoot. Dari kebanyakan waktu latihan ekstrakurikuler bolabasket yaitu dua kali dalam seminggu mulai pukul 15.30 WIB sampai pukul 17.00 WIB. Dari kejadian apa yang tersaji dalam pembahasan diatas kurangnya intensitas latihan tersebut tentunya berpengaruh terhadap tingkat kesegaran jasmani seorang atlet. Seseorang yang akan melakukan aktivitas olahraga secara teratur dan sesuai dengan kebutuhan maka akan memperoleh kesegaran jasmani yang baik. Atlet berbakat akan menghabiskan berjam-jam dalam latihan dalam meningkatkan keterampilan yang sangat penting dalam olahraga yang dipilih (Ward, Hodges, Starkes, \& Williams, 2007). Menurut Tri Ani Hastuti (2008:63) usaha peningkatan kesegaran jasmani harus dilaksanakan seseorang minimal 3-4 kali seminggu selama 30-45 menit setiap melakukan aktivitas jasmani. Dari apa yang dikatakan ahli sebelumnya apabila kita mengacu pada pernyataan tersebut, tentunya latihan yang dilakukan dalam ekstrakurikuler bolabasket di Yogyakarta masih kurang karena hanya dilaksanakan dua kali dalam seminggu.

Berkaitan dengan shooting merupakan teknik sasaran akhir dalam bermain bolabasket. Keberhasilan suatu regu/tim selalu ditentukan oleh ketepatan dan banyaknya point dalam melakukan shooting. Pentingnya keterampilan dapat bervariasi diantara posisi bermain. Pemain basket bisa dibagi menjadi tiga posisi bermain yaitu guard, forward, center, yang masing-masing memiliki peran yang berbeda. Untuk mencapai persyaratan ini, suatu keterampilan yang berbeda diperlukan dalam bermain dengan baik di setiap posisi (Abdelkrim, Chaouachi, Chamari, Chtara, \& Castagna, 2010; Hoare, 2000; Sallet, Perrier, Ferret, Vitelli, \& Baverel, 2005). Untuk mendapatkan peluang dan keberhasilan dalam melakukan shooting diperlukan teknik yang benar. Shooting dalam permainan bolabasket dapat dilakukan dari berbagai sisi yaitu dari sisi kanan ring, dari sisi kiri ring, dan dari sisi tengah. Pada sisi kanan dan kiri ring basket, papan pantul tidak berhadapan langsung dengan penembak, sehingga penembak harus bisa mencari sudut yang tepat agar bola masuk ke dalam keranjang. Seperti yang dikemukakan oleh Lieberman-Cline (1997:102) bahwa sudut $45^{\circ}$ adalah posisi yang tepat bagi penembak bank shoot (menembak melalui papan pantul), pemain bolabasket lebih sering melakukan teknik shooting melalui papan pantul untuk mencetak skor, terutama pada saat pemain menyerang pada sudut $45^{\circ}$ dari papan ring. Pada saat penyerangan bola lebih sering dioper ke sisi kanan dan kiri daripada ke sisi tengah, dan taktik penyerangan tersebut lebih sering berhasil untuk mencetak skor.

Kontrol bola sangat penting keterampilan untuk pemain bola basket, sejak menggiring bola sambil berganti diperlukan arahan untuk mencapai pertunjukan yang sukses (Cortis et al., 2011; Fujii,Yamada, \& Oda, 2010; Torres-Undaet al.,2013). Penguasaan gerakan shooting anggota ekstrakurikuler bolabasket putra usia 11-14 tahun di Yogyakarta dirasa masih kurang. Hal tersebut disebabkan oleh penguasaan teknik menembak yang belum benar. Sikap menembak yang seharusnya dengan posisi lengan seperti huruf L, namun beberapa pemain bolabasket masih menembak dengan posisi lengan seperti huruf $\mathrm{V}$ dan beberapa posisi siku pemain masih keluar badan. Lengan anak juga kurang kuat untuk melakukan shooting, sehingga banyak shooting yang tidak sampai ke ring. Kemampuan shoting bola basket sangat dipengaruhi pula dengan beberapa teknik, teknik yang mudah dalam melakukan shooting adalah dengan melempar dengan memantulkan bola ke papan baru bola akan masuk. Teknik memantulkan bola ke papan ini dinamakan dengan Bank Shoot.

Berdasarkan latar belakang di atas, maka peneliti ingin melakukan penelitian untuk mengetahui perbedaan kemampuan bank shoot dari sisi kanan dan kiri pada anggota ekstrakurikuler bolabasket putera musia 11-14 tahun di Yogyakarta

\section{METODE}

Penelitian ini menggunakan metode survey dengan teknik tes dan pengukuran. Sebagai tujuan penelitian adalah untuk mengetahui ada atau tidaknya adanya hubungan 
kemampuan antara bank shoot dari sisi kanan dan kiri pada anggota ekstrakurikuler bolabasket.Jenis Penelitian ini merupakan penelitian komparatif. Penelitian komparatif adalah penelitian yang berusaha untuk menemukan persamaan dan perbedaan tentang benda, tentang orang, tentang prosedur kerja, tentang ide-ide, kritik terhadap orang, kelompok, terhadap suatu ide atau suatu prosedur kerja (Aswarni Sujud dalam Suharsimi Arikunto, 2002: 236).Waktu dan Tempat Penelitian Penelitian dilakukan Bulan Januari dan februari 2019. Pengambilan data penelitian dilakukan pada bulan Januari 2019 di lapangan bolabasket SMK Negeri 3 Yogyakarta, pada pukul 15.00 WIB. Target/Subjek penelitian dalam penelitian ini meliputi seluruh anggota ekstrakurikuler bolabasket putera Usia 11-14 tahun di Yogyakarta. Sampel dalam penelitian ini diambil secara random sampling dengan jumlah 30 siswa.

\section{HASIL DAN PEMBAHASAN}

Analisis data dengan ujji prasyarat dan uji $t$. Selain itu analisis data digunakan untuk mengetahui perbedaan bank shoot dari sisi kiri dan sisi kanan maka dengan membandingkan mean bank shoot dari hasil tes sisi kiri dan tes sisi kanan sehingga diketahui mana yang terbaik. Rumus perhitungan mean (rata-rata) adalah sebagai berikut: Keterangan: $\mathrm{Me}=$ Mean (rata-rata),$\sum=$ Epsilon (jumlah), $\mathrm{X}=$ nilai i sampai $\mathrm{n}, \mathrm{N}=$ jumlah individu

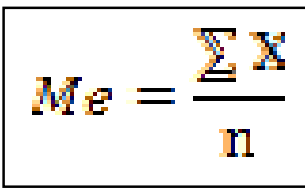

Tabel 1. Frekuensi Data Perbandingan bank shoot sisi kanan dan kiri

\begin{tabular}{|l|r|r|}
\hline & \multicolumn{1}{|c|}{ Kanan } & \multicolumn{1}{|c|}{ Kiri } \\
\hline Nilai Minimum & 19,00 & 9,00 \\
\hline Nilai Maksimum & 14,00 & 15,00 \\
\hline Rerata & 10,67 & 11,20 \\
\hline Median & 10,00 & 11,00 \\
\hline Modus & 10,00 & 10,00 \\
\hline Std. Deviasi & 1,39 & 1,61 \\
\hline
\end{tabular}

Menurut tabel diatas hasil menunjukkan frekuensi perbandingan antara bank shoot dari sisi kanan dan sisi kiri, dengan nilai rata-rata bank shoot dari sisi kanan adalah 10,67 dan nilai rata-rata bank shoot dari sisi kiri adalah 11,20. Dari hasil tersebut bisa di katakan karena nilai rata-rata bank shoot dari sisi kiri lebih besar dari nilai rata-rata bank shoot dari sisi kanan, maka disebutkan sisi dari sebelah kiri dianggap lebih efektif dalam melakukan bank shoot dari pada melakukan bank shoot dari sbelah kanan. 


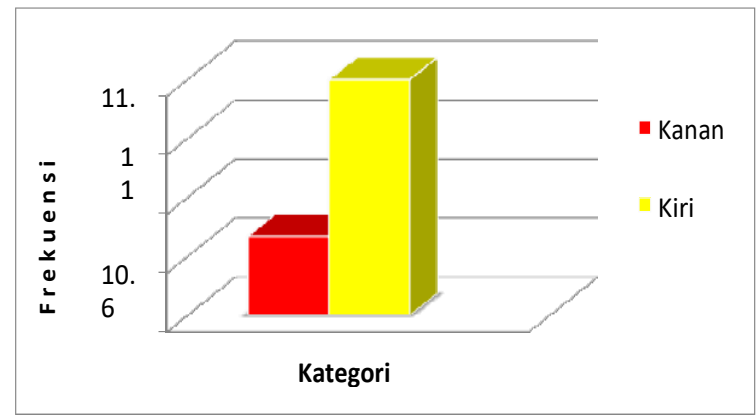

Gambar 1. Histogram rata-rata bank shoot sisi kanan dan kiri

Terdapat perbedaan signifikan yaitu apabila nilai signifikan lebih besar dari 0,05 (signifikan > 0,05) maka Ha ditolak dan jika signifikan kurang dari 0,05 (signifikan < 0,05) maka Ha diterima.

Tabel 2. Uji-t bank shoot dari sisi kanan dan kiri

\begin{tabular}{|l|c|c|c|c|}
\hline \multirow{2}{*}{ Variabel } & \multicolumn{3}{|c|}{ Uji-t } & \multirow{2}{*}{ Keterangan } \\
\cline { 2 - 5 } & $\begin{array}{c}\text { Hitun } \\
\mathrm{g}\end{array}$ & $\mathrm{df}$ & Sig. & \\
\hline $\begin{array}{l}\text { Bank Shoot } \\
\text { sisi kanan dan } \\
\text { kiri }\end{array}$ & $-1,417$ & 14 & 0,178 & $\begin{array}{c}\text { Tidak } \\
\text { Signifikan }\end{array}$ \\
\hline
\end{tabular}

Hipotesis awal (Ho) mengatakan tidak ada perbedaan yang signifikan antara kemampuan bank shoot anggota ekstrakurikuler bolabasket putra usia 11-14 tahun di yogyakarta. Hipotesis alternatif (Ha) mengatakan bahwa ada perbedaan yang signifikan antara bank shoot dari sisi kanan dan kiri pada anggota ekstrakurikuler bolabasket putra usia 11-14 tahun di yogyakarta. Kaidah yang digunakan untuk mengetahui ada atau tidak adanya uji-t antara bank shoot sisi kanan dan kiri memiliki nilai t hitung -1,417, $\mathrm{p}=0,178$, karena p > 0,05 maka tidak terdapat perbedaan signifikan antara bank shoot dari sisi kanan dan kiri. Nilai rata-rata (tabel 1), Hasil diketahui nilai rata-rata sisi kanan 10,67 dan nilai rata-rata sisi kiri 11,20, Berdasarkan hasil rata-rata tersebut bahwa karena nilai rata-rata bank shoot dari sisi kiri lebih besar dari rata-rata bank shoot dari sisi kiri, maka melakukan bank shoot dari sisi sebelah kiri lebih efktif dalam melakukan bank shoot, bagi anak normal (tidak kidal).

Adapun perbedaan sebuah kemampuan shooting atau menembak yaitu bank shoot dari sisi sebalah kanan dan sisi sebelah kiri disebabkan oleh beberapa faktor. Dapat dikatakan bahwa sebuah tembakan yang efisien adalah jika seorang penembak mendapat tembakan yang bagus dan dalam bola basket dapat tercapai ketika sebuah tim menciptakan peluang atau sebuah situasi di dekat keranjang atau ring basket tanpa kehadiran aktif pemain bertahan. Fakta ini bertepatan dengan hasil beberapa peneliti sebelumnya yang mengidentifikasi persentase penembakan 2 poin (Hofler dan Payne, 1997; Markoski et al., 2012; Pojskic et al.,2009; Russo et al.,2012). Seperti yang dikemukakan oleh Dedy Sumiyarsono (2002: 32) bahwa keberhasilan shooting dipengaruhi oleh beberapa faktor antara lain jarak, mobilitas, sikap menembak, ulangan tembakan, situasi dan suasana. Jarak melakukan shooting pada penelitian ini adalah sekitar 4,572 meter. Jarak tersebut merupakan jarak yang cukup bisa dijangkau untuk melakukan shooting oleh seorang pemain basket anak usia 11-14 tahun. Peserta tes masih sering terburu-buru dalam melakukan shooting yang mengakibatkan arah bola tidak terkendali. Sikap menembak peserta tes masih sering tidak 
pada posisi. Posisi shooting yang sebaiknya kaki sejajar, siku membentuk sudut $90^{\circ}$, tapi masih banyak peserta tes yang posisi kakinya masih depan belakang dan posisi siku yang terlalu menekuk. Akan tetapi bukan hanya faktor-faktor tersebut yang mempengaruhi keberhasilan suatu tembakan. Ada banyak faktor lain seperti busur lambungan, tingkat keterlatihan, kebiasaan, putaran bola.

Strategi dalam sebuah tim dalam menghadapi pertandingan merupakan sesuatu yang mutlak. Strategi shooting merupakan cara cukup bagus dan ada beberapa perlakuan yaitu lemparan bebas, medium shoot, 3 point shoot, bank shoot. Banyak peristiwa yang merupakan strategi mendasar ada lemparan bebas yang sukses jumlah yang besar tetapi tembakan tiga angka banyak yang gagal. Dari kejadian ini dapat disimpulkan bahwa itu peristiwa itu mungkin hasil dari rencana taktis tim. Kemampuan akan taktik dan strategi seorang pelatih akan berpotensi menjadikan keterampilan teknis pemain mereka lebih bagus, serta dapat mengembangkan strategi mereka yang berfokus pada lawan. Strategi defensif merupakan sebuah tindakan yang menyebabkan hasil dari tugas yang akurat oleh sebab itu para pemain harus membuat keputusan yang benar selama pertandingan dan dapat memilih melakukan tembakan dengan benar dan akurat. Hal Ini akan menghasilkan efektivitas perlakuan yang lebih baik dari tembakan yang lain, dan dengan demikian beberapa jumlah poin yang lebih tinggi akan terjadi. Pengaruh strategi pertahanan yang digunakan oleh lawan atau zone defend akan menjadi sebuah tekanan pada pemain yang biasanya menyelesaikan sebuah serangan dengan menggunakan tembakan, yang tampaknya menjadi elemen sangat penting dari sebuah permainan bolabasket (Daskalovski, Naumovski, \& Kocić, 2014; McCormick et al., 2014)

Apabila tim saat merancang sebuah strategi serangan yang bagus untuk tim, yang harus diperhatikan oleh pelatih adalah memperhitungkan seorang penembak yang potensial didalam tim tersebut dan seorang pelatih dapat menerapkan taktik yang memungkinkan setiap pemain menggunakan bakat individu mereka dengan baik dan secara berurutan untuk menyelesaikan sebanyak mungkin tindakan secara efektif dan efisien dalam melakukan tembakan (Marmarinos, Apostolidis, Kostopoulos, \& Apostolidis, 2016; Passos et al., 2011; Raiola, Altavilla, Tafuri, \& Lipoma, 2016). Dapat diamamti bahwa beberapa anggota ekstrakurikuler bolabasket putra usia 11-14 tahun di yogyakarta ketika sedang melakukan shooting mengambil busur lambungan bola yang datar, sehingga kemungkinan besar bola akan mengenai bagian lengkung cincin depan atau belakang dan bola akan terbuang jauh. Saat melakukan shooting jika sudah mengarahkan bola hendaknya tidak pada sasaran ring yang di lakukan tetapi sasaran papan pantul. Papan pantul merupakan cara dimana pandangan seorang penembak agar tidak terlalu datar dalam lambungan bola saat shooting. Dalam kata lain shooting yang baik adalah ketika lambungan bola itu sedang, tidak terlalu datar dan tidak terlalu tinggi. Bola yang lambungannya sedang akan lebih mudah untuk dikendalikan ke sasaran, pantulannya akan terbuang jauh secara vertikal dari daerah ring basket, sehingga bola dimungkinkan masih dapat masuk setelah memantul. Semakin tinggi lambungan bola, semakin sulit bola untuk dikontrol kearah sasaran.

Keterlatihan seorang atlet sangat penting jika diukur untuk keberhasilan suatu tembakan atau shooting. Semakin banyak frekuensi latihan dalam menembak ke ring, maka keterampilan shooting akan semakin matang. Selain itu bolabasket tidak lepas dari kebiasaan atau habbit, oleh sebab itu kebiasaan teknik shooting dalam melakukan sebuah tembakan juga berpengaruh terhadap keberhasilan dalam memasukan bola ke ring basket. Oleh sebab itu dari hasil dari tes kemampuan bank shoot dari sisi kanan dan kiri pada anggota ekstrakurikuler bolabasket putra usia 11-14 tahun di yogyakarta menunjukkan bahwa anggota tim bolabasket putra lebih baik dalam melakukan shooting dari sisi kiri dari pada sisi kanan. 


\section{SIMPULAN}

Berdasarkan analisis hasil penelitian dan pembahasan, dapat disimpulkan bahwa kemampuan bank shoot dari sisi kanan dan sisi kiri tidak terdapat perbedaan yang signifikan antara kemampuan bank shoot dari sisi kanan dan kiri pada anggota ekstrakurikuler bolabasket putra usia 11-14 tahun di yogyakarta, Tetapi dari hasil yang diperoleh bahwa bank shoot sisi sebelah kiri lebih efektif dibandingkan dengan bank shoot sisi sebelah kanan. Dari apa yang sudah diketahui diatas dan berdasarkan kesimpulan penelitian yang sudah disajikan bahwa ada beberapa saran yang bisa diberikan, yaitu bagi guru dan pelatih bola basket, hendaknya memperhatikan faktor-faktor yang mempengaruhi bank shoot saat membina atlet atau siswa.Bagi siswa agar menambah latihan-latihan lain yang mempengaruhi kemampuan bank shoot dari sisi kanan dan kiri, caranya seperti kekuatan otot, koordinasi mata tangan, dan lain sebagainya. Bagi peneliti selanjutnya agar sampel yang digunakan lebih besar lagi serta melakukan kontrol terhadap faktor-faktor yang dapat mempengaruhi keterampilan bank shoot dari sisi kanan dan kiri, seperti kondisi tubuh, faktor psikologi, dan sebagainya

\section{DAFTAR PUSTAKA}

Abdelkrim, N. B., Chaouachi, A., Chamari, K., Chtara, M., \& Castagna, C. (2010). Positional role and competitive-level differences in elite level men's basketball players. Journal of Strength \& Conditioning Research, 24(5), 1346-1355. doi:10.1519/JSC.0b013e3181cf7510

Choi, H., O'Donoghue, P.G. and Hughes, M.D. (2006), A Study of team performance indicators by separated time scale using a real-time analysis technique within IEnglish national basketball league. In H. Dancs, M.D. Hughes \& P. O’Donoghue (Eds.) World Congress of Performance Analysis of Sport VII - Book of Proceedings (pp.125-128). Cardiff: UWIC.

Collins and Hodges. (1978). A Comprehensive Guide to Sport Skill Test and Measurement. USA: Charles $\mathrm{C}$ Thomas.

Conte, D., Favero, T. G., Lupo, C., Francioni, F. M., Capranica, L., \& Tessitore, A.(2015). Time-motion analysis of Italian elite women's basketball games: Individual and team analyses. Journal of Strength and Conditioning Research, 29(1), 144-150. doi:10.1519/JSC.0000000000000633

Cortis, C., Tessitore, A., Lupo, C., Pesce, C., Fossile, E., Figura, F., \& Capranica, L. (2011). Inter-limb coordination, strength, jump, and sprint performances following a youth men's basketball game. Journal of Strength \& Conditioning Research, 25(1), 135142. doi:10.1519/JSC.0b013e3181bde2ec

Csataljay, G., James, N., Hughes, M. and Dancs, H. (2012), Performance differences between winning and losing basketball teams during close, balanced and unbalanced quarters. Journal of Human Sport and Exercise, 7(2), 356-364.

Csataljay, G., O’Donoghue, P., Hughes, M.D. and Dancs, H. (2009), Performance indicators that distinguish winning and losing teams in basketball. International Journal of Performance Analysis in Sport, 9(1), 60-66.

Daskalovski, B., Naumovski, M., \& Kocić, M. (2014). Multivariate and univariate differences in offense-defense variables among the best basketball leagues. Research in Physical Education, Sport and Health, 3(1), 99-103.

Dedy Sumiyarsono. (2002). Keterampilan Bola Basket. Surakarta:Yudhistira.

Fujii, K., Yamada, Y., \& Oda, S. (2010). Skilled basketball players rotate their shoulders more during running while dribbling. Perceptual and Motor Skills, 110(3), 983-994. doi:10.2466/pms.110.3.983-994 
Gomez, M. A., Tsamourtzis, E. and Lorenzo A. (2006), Defensive systems in basketball ball possessions. International Journal of Performance Analysis in Sport, 6(1), 98-107.

Gomez, M.A. Calvo, L.A. and Toro, O.E. (2006a). Differences between winning and losing under-16 male basketball teams. In H. Dancs, M.D. Hughes \& P. O’Donoghue (Eds.) World Congress of Performance Analysis of Sport VII - Book of Proceedings (pp.142-149). Cardiff: UWI

Hoare, D. G. (2000). Predicting success in junior elite basketball players - the contribution of anthropometric and physiological attributes. Journal of Science and Medicine in Sport, 3(4), 391-405. doi:10.1016/S1440-2440(00)80006-7

Hofler, R.A., and Payne, J.E. (1997), Measuring efficiency in the National Basketball Association. Economics letters, 55, 293-299.

Ibanez, S. J., Garcia, H., Feu, S., Lorenzo, A. and Sampaio J. (2009), Effects of consecutivebasketball games on the game-related statistics that discriminate winner and losing teams. Journal of Sports Science and Medicine, 8, 458-462

Ibanez, S. J., Sampaio, J., Feu, S., Lorenzo, A., Gomez, A.M. and Ortega, E. (2008), Basketball game-related statistics that discriminate between teams' season-long success. European Journal of Sport Science, 8(6), 369-372.

Imam Sodikun. (1992). Olahraga Pilihan Bola Basket. Jakarta: Dirjen Dikti.

Lieberman-Cline, Nancy.(1997). Panduan Lengkap Bola Basket untuk Wanita. Jakarta: PT.Raja Grafindo Persada.

Lorenzo, A., Gomez, M.A., Ortega, E., Ibanez, S.J. and Sampaio, J. (2010), Game related statistics which discriminated between winning and losing under-16 male basketball games. Journal of Sports Science and Medicine, 9, 664-668.

Markoski, B., Ivankovic, Z. and Ivkovic M. (2012), Using Neural Networks in Preparing and Analysis of Basketball Scouting. In A. Karahoca (Ed.), Data Mining Applications in Engineering and Medicine. InTech. Retrieved from: http://dx.doi.org/10.5772/48178

Marmarinos, C., Apostolidis, N., Kostopoulos, N., \& Apostolidis, A. (2016). Efficacy of the "pick and roll" offense in top level European basketball teams. Journal of Human Kinetics, 51, 121-129.

Nugraha, M. F. A, Rismayanthi, C. (2017). Profil Daya Tahan Aerobik Posisi Guard, Forward, dan, Centre Atlrt Bola Basket. Medikora. 16(1). 45-55 from : https://journal.uny.ac.id/index.php/medikora/article/view/23480

Okazaki, V. H. A., Rodacki, A. L. F., \& Satern, M. N. (2015). A review on the basketball jump shot. Sports Biomechanics, 14(2), 190-205.

Passos, P., Milho, J., Fonseca, S., Borges, J., Araujo, D., \& Davids, K. (2011). Interpersonal distance regulates functional grouping tendencies of agents in team sports. Journal of Motor Behavior, 43, 155-163.

Pojskic; H., Separovic, V. and Uzicanin, E. (2009), Differences between successful and unsuccessful basketball teams on the final Olympic tournament. Acta Kinesiologica, $3(2), 110-114$.

Raiola, G., Altavilla, G., Tafuri, D., \& Lipoma, M. (2016). Analysis of learning a basketball shot. Journal of Physical Education and Sport, 16(1), 3-7.

Russo, L., Miglietta, G. and Izzo, R.E. (2012), Research on performance indicators from game-related statistics in male basketball European Championship. In I. Jirasek, J. Kosiewicz \& D.N. Jr. Roberson (Eds). Sport and Physical Culture in the Mirror of the Social Sciences - Electronic Proceedings Book of The 3rd International Society for the Social Sciences of Sport Conference (pp.64-70). Olomouc: Palacký University. Retrieved from: http://www.issss2011.upol.cz/ 
Sallet, P., Perrier, D., Ferret, J. M., Vitelli, V., \& Baverel, G. (2005). Physiological differences in professional basketball players as a function of playing position and level of play. Journal of Sports Medicine and Physical Fitness, 45(3), 291-294.

Sampaio, J. and Janeira, M. (2003), Statistical analysis of basketball team performance: understanding teams' wins and losses according to a different index of ball possessions. International Journal of Performance Analysis in Sport, 3(1), 40-49.

Scanlan, A. T., Dascombe, B. J., Reaburn, P., \& Dalbo, V. J. (2012). The physiological and activity demands experienced by Australian female basketball players during competition. Journal of Science and Medicine in Sport, 15(4), 341-347

Suharsimi Arikunto. (2002). Prosedur Penelitian Suatu Pendekatan Praktik. Edisi revisi. Jakarta: PT Rineka Cipta.

Torres-Unda, J., Zarrazquin, I., Gil, J., Ruiz, F., Irazusta, A., Kortajarena, M., . . .Irazusta, J. (2013). Anthropometric, physiological and maturational characteristics in selected elite and non-elite male adolescent basketball players. Journal of Sports Sciences, 31(2), 196-203. doi:10.1080/02640414.2012.725133

Tri Ani Hastuti. (2008). Kontribusi Ekstrakurikuler Bolabasket Terhadap Pembibitan Atlet dan Peningkatan Kesegaran Jasmani "Jurnal Penedidikan Jasmani Indonesia". Yogyakarta: Jurusan Pendidikan Olahraga FIK UNY.

Ward, P., Hodges, N. J., Starkes, J. L., \& Williams, M. (2007). The road to excellence: Deliberate practice and the development of expertise. High Ability Studies, 18(2), 119-153. doi:10.1080/13598130701709715 